\title{
A plea for a linguistic distinction between explanation and argument
}

\author{
THIERRY HERMAN
}

EFLE and Institute of Language Sciences and Communication

Universities of Lausanne and Neuchâtel

Switzerland

Thierry.Herman@unil.ch

\begin{abstract}
There is no clear consensus about a difference between explanation and argument. Having explained why traditional points of view of informal logic are problematic, I'll argue for a linguistic point of view on this question and show how rhetorical strategic moves can exploit the blurry frontier between explanation and argumentation. It seems necessary to introduce a third category - "apparent explanation" and two French connectives - "car" and "parce que" - will be used to describe differences.
\end{abstract}

KEYWORDS: Explanation, argument, informal logic, linguistics, connectives, car, parce que.

\section{INTRODUCTION}

The aim of this paper is to offer a slightly new point of view on a very old and common problem: how to distinguish between explanation and argumentation? I will offer here a linguist's point of view on this problem, which is often tackled by philosophers and critical thinkers. After explaining the linguistic clues I use to distinguish explanation and argument, I will discuss rhetorical strategies that take the appearance of an explanation to fulfil argumentative purposes. During this examination, I will point out uses of the French connectives "car" and "parce que", but non-French speakers will be able to understand what I would like to underline.

Broadly speaking, two points of view on the difference between explanation and argumentation can be found in literature. The first one is more philosophical, dealing mainly with informal logic and critical thinking and the second one is dealing with linguistics, which is perhaps less known outside French tradition on argumentation. There are problems within each of these approaches: the old issue of differences between explanation and argumentation is still not resolved. Recently, McKeon (2013) argued for example that explanations should be considered as arguments. On the other side, Trudy Govier (Govier, 2005) has written that explanations and arguments are different, but some explanations can nevertheless be seen as arguments within different contexts.

For his part, the French linguist Jean-Michel Adam considers that explanations and arguments adopt different patterns, called sequences. He argued in a seminal book that an argumentative sequence (inspired from Toulmin's model) differs from an explicative sequence by the explicit presence in the latter of a problem and a solution. Thus, example 1 must be seen as an explanation: 
(1) Why should I stop smoking? Because, as soon as I run, I get breathless.

An explanation, according to Adam (Adam, 2011), ties together four "propositions" (not in the logical sense of the term): Proposition exp. 0: Introduction; P. exp. 1: Problem or Question (Why P? How P?); P. exp. 2: Solution or Answer (Because Q) and P. exp. 3: Conclusion - Evaluation. The presence of an explicit question and its immediate answer introduced by because (P. exp. 2 and P. exp. 3) seems to be the criteria to distinguish explanation from argumentation. The problem is that example (2) would probably be seen as an argumentative sequence in Adam's viewpoint.

(2) I should stop smoking, because as soon as I run, I get breathless.

The problem of these two similar examples is that a conclusion can be an explanandum and that premises can function as an explanans, just because of the presence of a whyquestion. This sudden change of nature of the sequence seems unsatisfactory, since the semantic point of view within these clauses appears untouched.

In the philosophical approach, problems arise because of several difficulties rightfully underlined by Govier (1987):

1. [...] 'thus' [may be] used in the paradigmatic logical role, preceding the conclusion in an argument. But in other cases, 'thus' functions just as naturally in an explanation.

2. According to the classic deductive-nomological account, explanation is one type of argument. Although this account is now widely criticized, it was dominant in the philosophy of science for several decades and still enjoys influence.

3. As many informal logic teachers have observed for their displeasure, it is very difficult to teach students the distinction between explanation and argument. They find it hard to grasp in theory and still more difficult to apply in practice.

4. Even when the distinction is grasped in theory, many passages, real or invented, can be interpreted as either explanation or argument. (Govier 1987, p. 159 - 160)

The first quotation illustrates that the same connectives can be used in argumentation and explanation; this is also the case in French. The second one points out that, historically, explanation was just an argument scheme; thus explanation was seen as a category inside argument. The third one illustrates a very common pedagogical problem: a lot of people, including students but not excluding teachers, do not understand the difference between explanation and argumentation. The last one, finally, emphasizes either an empirical problem of some unclassified examples or an insufficiency of theory that prevents from distinguishing between explanation and argument. Why is it so difficult to grasp the difference between these two types of discursive patterns? Answering this question requires to understand first how they are both defined.

To sum up the general frame in which explanations and arguments are distinguished, one could start by stating that: "Arguments offer justifications; explanations offer understanding" (Govier, 2005, p. 21). In other words:

In order for a collection $\mathrm{C}$ of propositions to represent one's evidential reasons for a proposition $\mathrm{P}$, one must be more certain of the propositions in $C$ than one is of P. (2) In order for a collection C of propositions to represent one's explanatory reasons for a proposition $\mathrm{P}$, one needn't be more certain of the propositions in $\mathrm{C}$ than one is of $\mathrm{P}$ (McKeon, 2013, pp. 286-287) 
This leads to consider that " $(\mathrm{P})$ Carole is the best math student in the class, $(\mathrm{Q})$ because she is the only student in the class who is going to a special program for gifted students" (Govier, 2005, p. 22) may be interpreted as an explanation if everyone knows (P) but as an argument if the addressee must be convinced that $(\mathrm{P})$ is true. Hence, the difference between argumentation and explanation depends on the addressee's knowledge.

But this view, which is unstable - as Govier's example of Carole reveals - may also be unsatisfactory. I would like to highlight three problems related to this kind of philosophical account in the next sections.

\section{PROBLEMS WITH THE PHILOSOPHICAL ACCOUNT}

The first problem is that certainty is viewed as an evaluation by the addressee. McKeon argues against Govier's premise that "one must be more certain of the propositions in C than one is of P" (McKeon 2013: 286), writing: "[Govier's premise] is false. [...] I am certain of $\mathrm{A}$ and $\mathrm{B}$, but not of $\mathrm{C}$. I come to see that $\mathrm{A}$ and $\mathrm{B}$ are evidential reasons for $\mathrm{C}$ and as a consequence I become equally certain of C [...]" (McKeon 2013, p. 287). This counter-argument highlights the pronoun "I", which is clearly the addressee's epistemic evaluation of $\mathrm{C}$, between uncertainty and certainty. Thus, certainty appears to be a cognitive reality and not a linguistic feature. It raises the problem of the accessibility of an evaluation of certainty for any analyst. This lack of a clear-cut criterion about addressee's evaluation prevents any analyst from settling between explanation and argument in ambiguous cases.

As a linguist, my solution is not to evaluate cognitive certainty but to describe how it is linguistically encoded. Works on epistemic modality ${ }^{1}$ epitomize this view on certainty to the extent that "manually annotate and consequently automate identification of statements with an explicitly expressed certainty or doubt, or shades of epistemic qualifications in between" (Rubin, 2010, p. 535) can now be done. It means that a discourse analyst interested in evaluating whether a statement is an explanation or an argument should focus on certainty encoded by the speaker's rather than the addressee's evaluation. Within this frame, only absolute certainty (the highest of the five levels described by (Rubin, Liddy, \& Kando, 2006; Rubin, 2010)) is a relevant category for explanation.

The second problem with the - broadly considered - philosophical account is also tied with cognitive contingencies. Context-dependency is quite a hurdle in this case. These two quotations illustrate the problem [italics are mine]:

Passages that appear to be arguments are sometimes not arguments but explanations. The appearance of words that are common indicators [...] cannot settle the matter, because those words are used in both explanations and arguments. We need to know the intention of the author" (Copi \& Cohen, 2008, p. 19).

\footnotetext{
1 "Epistemic modality, or certainty, concerns a linguistic expression of an estimation of the likelihood that a certain hypothetical state of affairs is, has been, or will be true (Nuyts, 2001). Subtle linguistic clues, or markers, contribute toward the user's understanding of how much credibility can be attached to individual propositions and whether the information comes from the first-hand or second-hand sources" (Rubin, 2010, p. 535)
} 
In such a context, there would be no point in arguing for that claim, because there is no need to try to rationally persuade anyone that it is true; the people spoken to already believe it (Govier, 1987, p. 23).

My view, as a linguist and discourse analyst, is that we can only infer relevant intentions from what is said and make assumptions about the addressee's mental states (beliefs, desires, intentions, etc.) from a contextual point of view. Works by Grice (1975) or Sperber \& Wilson (1996) are typically used to calculate meaning from what has been said. On the other side, rhetoric is first defined by making adjustments with the addressees' beliefs and desires (Herman \& Oswald, 2014). Knowing intentions and beliefs is quite an impossible task, but a discourse analyst should make assumptions or hypotheses about these mental states and estimate their probability within a given context of communication.

The third philosophical problem is linked with a strong vision of truth. "Explaining why C [I should stop smoking] is true is the very same thing as giving a reason to think $\mathrm{C}$ is true" (Wright, 2002, p. 37) is a typical quotation that illustrates how truth evaluation is unavoidable in these matters or in order to settle the question. Linguists, on the other side, aren't generally interested in knowing the truth, but rather in showing how reality is represented.

(3) (P) Joe took the time machine, (A) because he needed digital pictures of Napoleon during the battle of Waterloo.

(3) will be seen as an explanation even if (P) is very likely to be false in 2014 and because $(\mathrm{P})$ is represented as real. Linguistic markers underline it: use of the simple past; act of an assertion; no doubt mentioned on an epistemic level. This utterance appears to be true and is intended to appear so for the addressee independently of our knowledge of the state of the world.

So, if we accept to get around these problems as I do with the linguist's points of view I've just underlined, we can define explanation as follows:

Explanation of a proposition $(\mathrm{P})$ by a proposition or a set of propositions $(\mathrm{Q})$ implies that $(\mathrm{P})$ is linguistically presented as indisputable, i.e. represented as true or as certain

This leads of course to another difficulty: what is linguistically indisputable? The key criterion I shall use here is linguistic modalities.

\section{USING LINGUISTIC MODALITIES}

I will rely here on the most thorough book on the subject in French, Laurent Gosselin's book published in 2010 (Gosselin, 2010), in which he details six types of linguistic modalities : alethic, epistemic, appreciative, axiological, boulomaïc and deontic modalities (logical modalities like necessity is treated within this system of modalities) . Of course, the modalities that are tied to the question of explanation are essentially alethic modality (truth represented) and epistemic modality on certitude (and degrees of certitude). Let's examine these two cases. 
"Alethic modality characterizes fundamentally descriptive judgments [it supposes preexisting facts and reports them] that refer to an existing reality, independently of judgments passed on it" (Gosselin $2010: 314$ ), my translation). Statements expressing alethic modality are not considered as standpoints, but as facts which cannot start with "I guess that" or "I find that" - see example 4. This is quite a good test to distinguish alethic modalities from epistemic ones.

(4) Albert is a widower $\rightarrow ? ?^{2}$ I guess that Albert is a widower

Conversely, epistemic modalities are linked with subjectivity. Gosselin talked about "subjective truth". It is difficult to insert a circumlocution like "No one could deny" before an epistemic utterance - see example 5 - without a sort of power grab on this utterance. Thus, epistemic modalities are always linked with a kind of evaluation. It could be a highly shared and quite obvious evaluation in certain contexts or a more personal one that appears to be generally admitted. There's no problem however to insert "I guess that" or "I find that" before the epistemic utterance.

(5) "Our economy is weakened" $\rightarrow$ I find that our economy is weakened vs. ? No one can deny that our economy is weakened

(6) "My computer is old" $\rightarrow$ I guess that my computer is old vs. ? No one could deny that my computer is old ${ }^{3}$

Alethic modality is quite clear: it is the only modality that necessarily leads to an explanation. Such statements are linguistically represented as true. Hence, any causal conjunction following an alethic statement $\mathrm{A}$ is designed to offer an explanation of it (why A? or How A?).

Dealing with epistemic modality is a bit more complex and confusing. Epistemic modality concerns "subjective truths", beliefs on objects of this world, "descriptive judgments which do not constitute value judgments, but which do not either put back to an autonomous reality" (Gosselin, 2010, p. 325). With epistemic modality, what is represented is not a matter of truth but a matter of certainty and a matter of degrees of certainty.

In principle, epistemic modality expressed in (7) leads to argumentation, since the conclusion is a subjective standpoint underlined by the modal verb (may) and provided that following arguments give reasons to justify beliefs.

(7) My computer may be too old now.

\footnotetext{
2 By convention, quotation marks signal not impossible utterances, but highly improbable (??) or strange (?) ones without a clearer context.

3 This example is echoing the problem of «language " and "speech " (Ferdinand de Saussure). « Old » in language in intrinsically evaluative and subjected to a point of view (I judge this as old), but its evaluative features can be irrelevant in certain contexts. If the computer mentioned in (6) is 2 years old, the personal evaluation will probably be very salient and probably challenged, but if it is an 18 years old computer, it is highly probable that, in this context, no one will deny its old age (see point 4 below).
} 
But there is a major problem with epistemic modality when the epistemic value is absolute certainty (e.g.: "My computer is old"). Here, the subjective part of the clause, which was inherent in the modal verb "may", seems erased by the certitude of the modal verb "to be". It remains, though, that "old" is an inherently subjective adjective, even if the evaluation seems shared or obvious. But it is not always the case and when epistemic modalities are rephrased as alethic ones, the result can have a powerful rhetorical effect see the move between (8) and (9).

(8) "It is estimated that there are 2 million weapons in Switzerland" $\rightarrow$ (9) "There are 2 million weapons in Switzerland"

With this kind of move, an evaluation of reality (8) is encoded as an alethic sentence (9) which is imposed (and counted) as a true fact. In this case, when reasons are provided, they appear as explanations. (9) is not expected to be contradicted or called into question by the addressee. This strategy offers a crucial advantage to the speaker, which is pointed out by Aristotle in Topics:

Not every problem, nor every thesis, should be examined, but only one which might puzzle one of those who need argument [...]. For people who are puzzled to know whether snow is white or not need perception. (Aristotle, Topics, I, part 11)

This move - transforming epistemic clauses into truly alethic utterances - uses what Danblon (2001) calls obviousness effect. A consequence of this effect is to let some premises or conclusions appear as not open to discussion or to justification or not expecting to be discussed - as some linguistic presuppositions do. Hence, it prevents the opening of a confrontation stage and, consequently, an argumentative dialogue according to the pragma-dialectical view on argumentation (Eemeren \& Grootendorst, 2004).

\section{PSEUDO-EXPLANATIONS}

There are also moves in which the speaker can exploit the blurring lines between explanation and argument without transforming modalities. In order to analyze such moves, one must decide if the conclusion of an argument or an explanation is represented as admitted. In other words, the analyst must evaluate if the speaker commits the audience to believe the reality described in the conclusive clause. This evaluation, based on linguistic clues, leads me to conclude that we need a third category between argument and explanation: a kind of pseudo-explanation where $(\mathrm{P})$ is considered as admitted and takes advantage of the certainty expressed to appear as explicative but can also be disputed as an argument, since it remains non-alethic.

Here are some cases of apparent explanations or pseudo-explanations:

The first case exploits the "invisible" epistemicity of non-axiologic evaluative terms: "Philip is tall", "Taxis are expensive". This move counts clearly on a supposed common ground, or a doxa, between speaker and audience. Language isn't sufficient per se and context is essential. If Philip is a classic European basketball player, probably no one will contest (P) "Philip is tall"; if he is a grown-up French man whose height is about 
$1 \mathrm{~m} 80$ (5.91 feet), (P) will probably be more disputable. If, finally, his height is about $1 \mathrm{~m} 55$ with the same contextual data, $(\mathrm{P})$ will probably be considered as ironic. Because the speaker counts on a collective acceptance on his/her claim, "Philip is tall, because he ate a lot of soup" can be counted as an explanation. Still, the "conclusion" part of it remains intrinsically epistemic and cannot be considered as "pure" explanation. Example (6) illustrates this case.

The second case is an echo of the first one. Doxa, general beliefs and stereotypes taken for granted - e.g. "French people eat cheese after the main course, because..." also offer apparent explanations. In this example, the speaker gives no linguistic clue that "the French eat cheese after the main course" is a disputable generalization. It is assessed as a monolithic truth. Hence, the audience is invited to consider it as true and nondisputable. Present tenses, iterative truths, generalities are some of the linguistic clues which point out taken for granted opinions. It must be underlined here that this case implies an absence of axiological and appreciative modalities in language (see infra). For example, "French people are disgusting frog-eaters" is clearly stereotypical, but the adjective "disgusting" is appreciative - implies (strong) speaker's subjectivity - and is not a pseudo-explanation for this reason.

The third and last case I can think of - without aiming at completeness in these observations - can be called an easy gamble on certainty. The future tense, even if it is inherently unknown and disputable, may encode a virtual certainty. "John will arrive at noon: he told me that he caught the 11:00 am train" offers an example where future can be taken for granted and represented as certain, provided that no unexpected incident appears. The weather forecast frequently offers this kind of prediction for the next day: "rain will fall tomorrow" is offered as certain and may be understood as a pseudoexplanation. In this context, it is interesting to underline that many weather forecasts mention a degree of probability in their previsions, recalling here that predictions are not as certain as they appear.

These cases have one common trait: they count on audience's acceptance. Now, in contrast, we may find alethic clauses that are in fact "an argument" without being explanation or pseudo-explanation. Inference to best explanation is, despite its name, an argumentative move. If (9) is alethic without further context, (P), in example (10), becomes epistemic, because $(\mathrm{Q})$ is used to establish the truth represented in $(\mathrm{P})$.

(9) John has left the party

(10) (P) John has left the party (I guess that John has left the party), (Q) because no one has seen him for an hour

Yet, the alethic form of $(\mathrm{P})$ hides the intrinsic uncertainty of the conclusion - only (Q) reveals that the truth of $(\mathrm{P})$ is not presupposed, but inferred. Note that "I am certain that John has left the party" is completely epistemic and appears paradoxically less certain than (9). In such cases, the process of establishing a conclusion implies in retrospect that (P) cannot be considered as true or certain. Hence, it cannot be an explanation. It is important to see that the alethic nature of $(\mathrm{P})$ disappears when it becomes clear that $(\mathrm{P})$ is inferred and not stated.

Apart from alethic and epistemic modalities, Gosselin defines axiological and appreciative modalities which are linked with an evaluative point of view. Both 
modalities are used when a speaker expresses not objects of belief, but objects of desire and value judgments, whether these value judgments are validated by the subjective view of the speaker (appreciative modality: "I love this movie") or by the collective view of an institution (axiological modality: "It is wrong to act like that"). In these two cases, utterances imply a complete commitment of the speaker to his point of view. These modalities are not represented as true or indisputable: speaker's commitment is intrinsically tied with a possible disagreement. Even when appreciative modalities are generalized, for instance in "This is a great movie", the subjective adjective "great" is intrinsically representing a subjective evaluative standpoint that isn't cancelled in generalization. Even if a lot of people can agree with axiological modalities - because they imply communities through institutions, norms, ethics - the fact that the speaker is committing him or herself to the value-based evaluation implies a possible (but often improbable) disputation. Hence, using these modalities in utterances that are followed by justifications is always an act of arguing in favour of a standpoint ${ }^{4}$.

Let's sum up our position, before examining how connectives can interact with this table.

\begin{tabular}{|c|c|c|}
\hline Linguistic representation & $\begin{array}{c}\text { Nature of } \\
\text { (P) because (Q) }\end{array}$ & Expectations \\
\hline $\begin{array}{c}\text { A. (P) is represented as a true } \\
\text { fact }\end{array}$ & Explanation & (P) will probably not be called \\
into question
\end{tabular}

Table 1: Explanation, apparent explanation and argumentation

\section{FRENCH CONNECTIVES IN INTERACTION WITH EXPLANATION AND ARGUMENT}

"Because" can be translated in French either by "parce que" or "car". The main difference is the following one: "Parce que" is generally and quite often connected to an explicative move:

"Affirmation that $\mathrm{P}$ has a cause $\mathrm{Q}$, in the phrase $\mathrm{P}$ parce que $\mathrm{Q}$ always takes for granted truth of $\mathrm{P}$. We start with $\mathrm{P}$, considered as undisputed and then we present its origin Q". (Groupe Lambda-1, 1975 , p. 59 , my translation)

This quotation of the seminal article on differences between those French connectives highlights that $\mathrm{P}$ can be taken for granted, even if $\mathrm{Q}$ is open to discussion.

\footnotetext{
${ }^{4}$ I won't speak here about deontic ("you must go !") and boulomaïc ("I want to eat pizza") modalities. They are often linked with commitments from the speaker, for example when the speaker is delivering a piece of advice ("You should lose weight") - hence, it is clearly open to argumentation; but, the problem addressed in this paper concerns only a part of deontic and boulomaïc modalities that are open to justification. Some deontic modalities, giving orders for example, are not even supposed to be questioned or explained.
} 
Hence, using "parce que" is a possible rhetorical strategy in order to make an argument appear as an explanation:

(11) According to Samy Chaar, who has met her some time ago, this nomination "is good news, because [parce que] we have avoided a war of succession" (Le Temps, October 10 2013, my translation).

Example (11) illustrates that the speaker seems to "forget" the evaluative (appreciative) modality contained in "good news" and offers this argumentative move as an explanation. The obviousness effect of "good news" included in an explicative move is an interesting power grab: the audience is supposed to accept the idea of "good news". This strategic move can be illustrated in table 1 as moving from case $\mathrm{C}$ to appear like case $\mathrm{A}$ or $\mathrm{B}$.

Unlike "parce que", "car" is exclusively argumentative:

Enunciation of Q is represented as being intended for justification of the enunciation of $\mathrm{P}$ (groupe lambda-1 $1975: 259$, my translation)

"Car" illustrates in fact a double meta-discursive move: "I've said P and I justify P by saying Q". "Car" doesn't directly provide a cause for P but a reason that justifies saying $\mathrm{P}$. This presupposes that $\mathrm{P}$ can be or is disputed. Therefore, "car" is strictly an argumentative indicator. Hence, when "car" is used with apparent explanations, it reveals inherently greater expectations to be called into question than with "parce que" and gives up "explicative appearance" to exhibit an argumentative nature. This move from case B in table 1 to case $\mathrm{C}$ can be illustrated by example 12:

(12) (P) The conference fee is expensive, (Q) because [CAR] the organizing committee must pay many students to do the job

The use of "car" instead of "parce que" reveals in fact that P may already be a disputed issue in a community which leads the speaker to a justification. The speaker acknowledges that $\mathrm{P}$ is a matter of concern or may lead to an open debate. Thus, the pseudo-explanation is in fact embedded in a real or potential argumentative situation.

Some examples are even stranger. In principle, if "car" is strictly argumentative, one shouldn't find "car" with alethic modality. It's not the case, as shown by examples (13) and (14):

(13) (P) Noël Mamère : "I'm leaving the Green Party, (Q) because [car] the party is captive of its factions" (Le Monde, September 26, 2013, p. 10, my translation).

(14) (P) Nelson Mandela's agony goes on (Q) because [car] "his soul isn't in peace", according to traditional chiefs who estimate that Mandela's ancestors are irritated by family quarrels (Tribune de Genève, June 30, 2013, my translation).

In these examples, $(\mathrm{P})$ are undisputed statements of fact. So, what are the effects of this "move" that leaves case A in table 1 to appear like case C?

From a contextual point of view, Noël Mamère's and Nelson Mandela's cases are clearly moving from a non-polemic linguistic explanation which is taking place in a 
polemic context. Even if the truth of $(\mathrm{P})$ isn't called into question, the causes in $(\mathrm{Q})$ are expected to be disputed. "Car", in these situations, reveals the speaker's selfconsciousness that his/her explanation will almost certainly create a dispute or arouse an opposition: disagreements about offered causes or about the link between $(\mathrm{P})$ and $(\mathrm{Q})$ are now expected.

This... explanation may enable us to understand an empirical test led by Sandrine Zufferey (2012). In this test, participants were asked to fill a blank within two clauses with either "parce que", "car" or "puisque" (since). Example (15) has delivered rather unexpected results.

(15) John laughed Peter stumbled

Indeed, $72,5 \%$ of participants put "parce que" $(72,5 \%)$ as a connective between these clauses whereas $27,5 \%$ participants prefer "car" $(27,5 \%)$. It is perfectly standard and expected to see a massive preference for "parce que" because of the alethic nature of "John laughed". But how is it possible to explain that more than a quarter of the respondents preferred "car"? It is difficult to answer, because there wasn't any situational context in this test. But in order to understand why "car" is still perceived as possible, one must probably admit that "car" shows a readiness for discussion. To be more specific, "car" indicates that "Peter stumbled" may be disputed as the true or the only cause of John's laughter.

\section{CONCLUSION}

We wanted to highlight in this paper that, in a linguistic perspective, two criteria must be used to make fruitful distinction between explanation and argument: one is a semantico-enunciative analysis of proposition $(\mathrm{P})$ which may be done with linguistic modalities; the second one is contextual expectation to be eventually called into question. These two criteria lead to distinguish in fact three categories: explanations, apparent explanations and arguments. We defined apparent or pseudo-explanations as non-alethic clauses explained or justified by some reason when these non-alethic clauses are expressed with an absolute certainty, i.e. taken for granted by the speaker, and do not contain appreciative or axiological modalities.

Strategic moves to open or to close a possible disputation must be analysed within this frame. We may find at least two cases: non-certainty bound modalities (appreciative modalities for example) may be linguistically encoded as generalized ("This is a wonderful movie"). In this case, it seems that the evaluative nature of this clause will remain as argumentative. But in the second case ("John is rich"), erasing the epistemic nature of this clause ("I think that John is rich") leads in fact to turn an argumentative move into an explanation.

Finally, the dynamics of some connectives (at least in French) is a way to analyse rhetorical and strategic moves: adding a layer of explanation on some intrinsic argument (some uses of "parce que") may be a way to impose as indisputable an argument; expressing in an explanation an expectation of plausible future argument (some rare cases of "car") leads to understand that the speaker is self-conscious of a potential disagreement either about the cause advanced or about the uniqueness of the presented cause. 
ACKNOWLEDGEMENTS: Thanks to Steve Oswald for the precious help in Amsterdam, to Jérôme Jacquin for the motivating moral support and to Thierry Raeber for his enthusiasm and nice ideas of linguistic tests.

\section{REFERENCES}

Adam, J.-M. (2011). Les textes types et prototypes: séquences descriptives, narratives, argumentatives, explicatives, dialogales et genres de l'injonction-instruction (Nouv. éd. entièrement rev. et augm). Paris: A. Colin.

Aristotle. (2014). Complete Works of Aristotle, Volume 1: The Revised Oxford Translation. Princeton University Press.

Copi, I. M., \& Cohen, C. (2008). Introduction to Logic (13 edition). Upper Saddle River, N.J: Prentice Hall. Danblon, E. (2001). La rationalité du discours épidictique. In M. Dominicy \& J.-M. Adam (Eds.), La mise en scène des valeurs: la rhétorique de l'éloge et du blâme (pp. 19-47). Lausanne; Paris: Delachaux et Niestlé.

Eemeren, F. H. van, \& Grootendorst, R. (2004). A systematic theory of argumentation: the pragmadialectical approach. Cambridge ; New York [etc.]: Cambridge Univ. Press.

Gosselin, L. (2010). Les modalités en français: la validation des représentations. Amsterdam ; New York: Ed. Rodopi.

Govier, T. (1987). Problems in argument analysis and evaluation. Dordrecht; Providence-U.S.A: Foris.

Govier, T. (2005). A practical study of argument (6th ed). Belmont [etc.]: Thomson Wadsworth.

Grice, H. P. (1975). Logic and conversation. In D. Davidson \& G. Harman (Eds.), The logic of grammar (pp. 64-75). Encino, Calif: Dickenson Pub. Co.

Groupe Lambda-1. (1975). Car, parce que, puisque. Revue Romane, 10, 248-280.

Herman, T., \& Oswald, S. (Eds.). (2014). Rhétorique et cognition: perspectives théoriques et stratégies persuasives / Rhetoric and cognition: theorical perspectives and persuasive strategies. Bern: P. Lang.

McKeon, M. W. (2013). On the Rationale for Distinguishing Arguments from Explanations. Argumentation, 27(3), 283-303. http://doi.org/10.1007/s10503-012-9288-1

Rubin, V. L. (2010). Epistemic modality: From uncertainty to certainty in the context of information seeking as interactions with texts. Information Processing \& Management, 46(5), 533-540. http://doi.org/10.1016/j.ipm.2010.02.006

Rubin, V. L., Liddy, E. D., \& Kando, N. (2006). Certainty Identification in Texts: Categorization Model and Manual Tagging Results. In J. G. Shanahan, Y. Qu, \& J. Wiebe (Eds.), Computing Attitude and Affect in Text: Theory and Applications (pp. 61-76). Springer Netherlands. Retrieved from http://link.springer.com/chapter/10.1007/1-4020-4102-0_7

Sperber, D. (1996). Relevance: Communication and Cognition (2 edition). Oxford; Cambridge, MA: Wiley-Blackwell.

Wright, L. (2002). Reasoning and Explaining. Argumentation, 16(1), 33-46. http://doi.org/10.1023/A:1014940822482

Zufferey, S. (2012). "Car, parce que, puisque" revisited: Three empirical studies on French causal connectives. Journal of Pragmatics, 44(2), 138-153. http://doi.org/10.1016/j.pragma.2011.09.018 